\title{
12. PALEOMAGNETISM AND ROCK MAGNETISM OF UPPER JURASSIC LIMESTONE AND BASALT FROM SITE 367
}

\author{
Dennis V. Kent and Lan Ping Tsai ${ }^{1}$, Lamont-Doherty Geological Observatory of Columbia University, \\ Palisades, New York
}

\begin{abstract}
Remanent magnetization measurements were made on 49 samples of upper Jurassic limestone varying in color from gray to red and 7 samples of basalt recovered at Site 367 . The gray limestones have very weak magnetizations and are of limited use paleomagnetically. The red limestones have stronger remanences and fair to good magnetic stabilities. The mean remanent inclination of the most reliable set of red limestone samples $(N=14)$ after 200 -oe $\mathrm{AF}$ demagnetization is $25^{\circ} \pm 5.1^{\circ}$, near the present axial dipole field inclination $\left(24^{\circ}\right)$ as well as the expected inclination of the Jurassic field $\left(21^{\circ}\right.$ to $\left.30^{\circ}\right)$ at the core site. A single stable reversed direction of magnetization (Sample 33-3, $88 \mathrm{~cm}$ ) may represent the earliest interval of reversed geomagnetic field polarity of the late Jurassic-early Cretaceous magnetic reversal sequence. The basalt samples had very unstable remanent magnetic properties, characterized by median demagnetizing fields less than $100 \mathrm{oe}$. The samples were able to acquire large viscous remanences (VRM) in the laboratory in a 1.0-oe field. Moreover, the intensity of VRM acquired in the presence of the NRM was at least a factor of five greater than that acquired under similar conditions but after AF demagnetization. The measured magnetic properties of these basalt samples suggest that the magnetic quiet zone in the general region of Site 367 may be due in part to reduction of magnetization contrast in the magnetized basement layer by viscous remagnetization.
\end{abstract}

\section{INTRODUCTION}

The magnetic properties of 49 samples of sediment and 7 samples of igneous rock from Site 367 were studied. The sediments sampled consisted of light gray and reddish-brown limestones of late Jurassic age; the purpose of their study was to determine the occurrence of remanent magnetizations of normal and reversed polarity that might be related to geomagnetic field reversals in the late Jurassic. The 7.2 meters of basalt recovered at Site 367 are believed to be from oceanic basement that may underlie the magnetic quiet zone bordering the African continent; representative samples of the basalt were studied to characterize remanent magnetic properties and magnetic mineralogy.

The partially oriented samples of limestone and basalt were in the form of $2.5-\mathrm{cm}$-diameter right circular cylinders. Measurements of remanent magnetization were made on a spinner magnetometer with a noise level of approximately $3 \times 10^{-7}$ emu (total moment). Initial susceptibilities were measured with a commercial AC bridge.

\footnotetext{
'Also Department of Geological Sciences, Columbia University.
}

\section{SEDIMENTS}

\section{NRM and $k$}

The limestone samples can be conveniently placed into two groups for discussion on the basis of their color: light gray limestones which occur commonly from Core 32 to the up-core limit of our sampling (Core 30 ) and reddish-brown limestones which occur stratigraphically below the gray limestones to near the contact with basalt (Core 38). The NRM intensities of the limestone samples vary over four orders of magnitude from about $3 \times 10^{-9} \mathrm{emu} / \mathrm{g}$ to $5 \times 10^{-5}$ $\mathrm{emu} / \mathrm{g}$; for the size of the samples, magnetizations less that about $5 \times 10^{-8} \mathrm{emu} / \mathrm{g}$ are within a factor of 5 of the instrument noise level and are not considered useful. The initial susceptibilities of all samples are distributed over a narrower range of values, from about $1 \times 10^{-6} \mathrm{cgs} / \mathrm{g}$ to $3 \times 10^{-5} \mathrm{cgs} / \mathrm{g}$. For both parameters, the distribution of values appears to be related to the color of the limestone samples. The red (gray) limestones typically have NRM intensities greater (less) than $1 \times 10^{-7} \mathrm{emu} / \mathrm{g}$ (Figure 1); the color separation with susceptibilities is not as pronounced, but the red limestones do have larger values on the average (Figure 2).

The larger NRM intensities and initial susceptibilities of the red limestones may reflect the presence of 


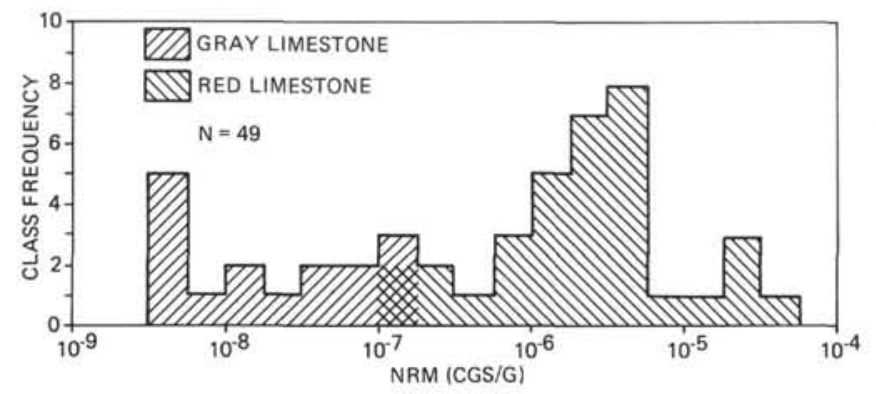

Figure 1. Intensities of natural remanent magnetism (NRM) of 49 specimens of limestone from Site 367. Grey limestones are from Cores 30 to 32; red limestones from Cores 33 to 38 .

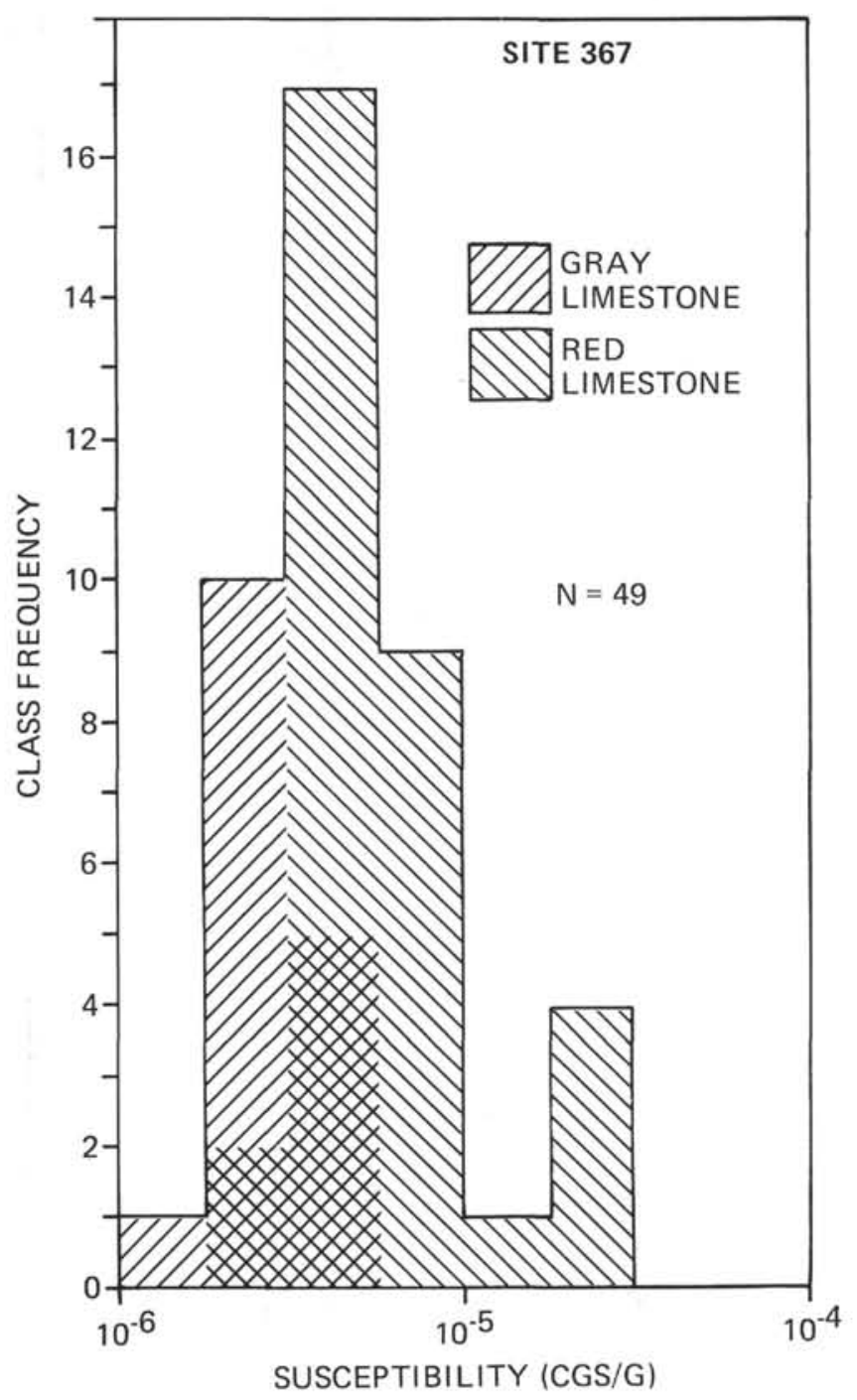

Figure 2. Initial susceptibilities of 49 specimens of limestone from Site 367. Grey limestones are from Cores 30 to 32 ; red limestones from Cores 33 to 38 .

an additional quantity of magnetic minerals in the red pigment that evidently does not occur to a marked extent in the gray limestones. This apparent difference in magnetic mineral concentration or type is less well reflected by the susceptibilities than by the NRM intensities, most likely because of a large contribution to the susceptibilities from paramagnetic and diamagnetic minerals.

\section{Stability and Direction of Magnetization}

The NRM of each limestone sample was remeasured after AF demagnetization in a field of 100 oe, and for the red limestone samples, in a field of 200 oe as well. Every third sample stratigraphically was subjected to stepwise AF demagnetization at smaller field intervals to 300 oe to investigate the stability of the NRM in greater detail. The change in direction and intensity of NRM with AF demagnetization in progressively higher fields for six representative samples is shown in Figure 3. The remanent inclination and declination directions and the fraction of the NRM intensity remaining after partial AF demagnetization of each sample are included in Table 1.

It was difficult to characterize the stability against alternating fields of the gray limestone samples due to their very weak NRM intensities. Some of the marginally more strongly magnetic gray limestone samples (e.g., Sample 32-4; $111 \mathrm{~cm}$; Figure 3) showed fair stability in NRM direction and intensity to alternating fields up to $150 \mathrm{oe}$. At higher demagnetizing fields the magnetizations were too weak to measure reliably. However, the change in remanent direction after AF demagnetization in 100 oe was more pronounced for most of the other gray limestone samples (Table 1), and this in conjunction with their very weak magnetizations allows little confidence to be placed in the gray limestone's remanent magnetization as a record of the paleomagnetic field.

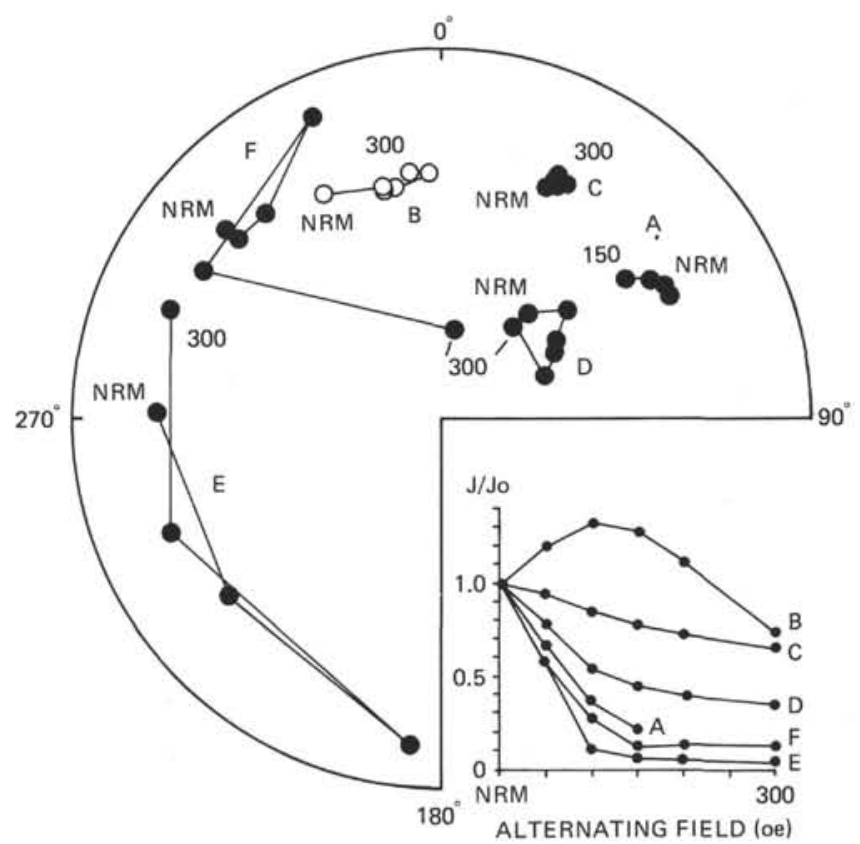

Figure 3. Change in direction and intensity of NRM with $A F$ demagnetization in progressively higher fields in six limestone samples: (a) 32-4, $111 \mathrm{~cm}$; (b) 33-3, $88 \mathrm{~cm}$; (c) 34-2, $21 \mathrm{~cm}$; (d) 35-2, $21 \mathrm{~cm}$; (e) 36-2, $35 \mathrm{~cm} ; 38-1$, $126 \mathrm{~cm}$. 
TABLE 1

Declination (D) and Inclination (I) of Natural Remanent Magnetization (NRM) and the Direction and the Fraction of the Initial NRM Intensity Remaining After AF Demagnetization for 49 Limestone Specimens, Site 367

\begin{tabular}{|c|c|c|c|c|c|c|c|c|}
\hline \multirow{2}{*}{$\begin{array}{c}\text { Sample } \\
\text { (Interval in } \mathrm{cm} \text { ) }\end{array}$} & \multicolumn{2}{|c|}{ NRM } & \multicolumn{4}{|c|}{100 oe } & \multicolumn{2}{|c|}{200 oe } \\
\hline & $\mathrm{D}\left({ }^{\circ}\right)$ & I $\left({ }^{\circ}\right)$ & $J_{100} / J_{\mathrm{NRM}}$ & $\mathrm{D}\left({ }^{\circ}\right)$ & I ( ) & $J_{200} / J_{\mathrm{NRM}}$ & $D\left({ }^{\circ}\right)$ & I $\left({ }^{\circ}\right)$ \\
\hline $30-1,10$ & 85.2 & -22.5 & 1.8 & 131.6 & -58.9 & - & - & - \\
\hline $30-1,144$ & 348.6 & -66.9 & 1.24 & 180.0 & 60.2 & - & - & - \\
\hline $30-2,53$ & 293.9 & 0.0 & 1.30 & 325.0 & 18.1 & - & - & - \\
\hline $30-2,138$ & 340.3 & -9.5 & 0.23 & 90.0 & -81.8 & - & - & - \\
\hline $31-1,24$ & 176.6 & 62.7 & 0.79 & 234.1 & 40.5 & - & - & - \\
\hline $31-1,125$ & 186.3 & 55.1 & 0.58 & 194.0 & 25.8 & - & - & - \\
\hline $31-2,53$ & 248.1 & 39.8 & 0.48 & 180.0 & 26.5 & - & - & - \\
\hline $31-2,105$ & 351.0 & 10.7 & 0.34 & 21.2 & -14.5 & - & - & - \\
\hline $32-1,95$ & 21.0 & 37.2 & 0.35 & 8.1 & 35.8 & - & - & - \\
\hline $32-2,52$ & 30.9 & 50.2 & 0.99 & 360.0 & -83.6 & - & - & - \\
\hline $32-2,100$ & 245.8 & 46.7 & 0.21 & 207.7 & 18.0 & - & - & - \\
\hline $32-3,35$ & 163.4 & 35.1 & 0.40 & 158.3 & 31.3 & - & - & - \\
\hline $32-3,104$ & 93.8 & 24.5 & 0.30 & 102.0 & 23.4 & - & - & - \\
\hline $32-4,25$ & 182.9 & 36.1 & 0.53 & 186.3 & 18.0 & - & - & - \\
\hline $32-4,111$ & 15.8 & 30.2 & 0.38 & 13.4 & 32.0 & - & - & - \\
\hline $32-5,25$ & 100.6 & 34.0 & 0.12 & 131.9 & -33.7 & - & - & - \\
\hline $32-5,100$ & 120.0 & 41.8 & 0.92 & 135.0 & 28.6 & 0.64 & 126.6 & 25.3 \\
\hline $33-1,13$ & 229.7 & 28.3 & 0.55 & 244.2 & 24.2 & 0.42 & 111.4 & 23.2 \\
\hline $33-1,112$ & 202.2 & 13.1 & 0.31 & 194.3 & 22.2 & 0.13 & 190.4 & 22.8 \\
\hline $33-2,25$ & 270.8 & 50.6 & 0.60 & 276.3 & 46.4 & 0.42 & 282.3 & 30.3 \\
\hline $33-2,103$ & 273.3 & 29.0 & 0.51 & 154.7 & 32.5 & 0.28 & 254.6 & 28.2 \\
\hline $33-3,10$ & 201.8 & 40.8 & 0.74 & 199.5 & 32.3 & 0.62 & 195.4 & 31.0 \\
\hline $33-3,88$ & 65.7 & -31.6 & 1.32 & 79.6 & -36.3 & 1.12 & 91.1 & -33.3 \\
\hline $34-1,54$ & 130.6 & 16.4 & 0.86 & 130.8 & 15.5 & 0.82 & 130.0 & 16.6 \\
\hline $34-1,125$ & 183.7 & 32.0 & 0.60 & 176.4 & 21.7 & 0.40 & 173.8 & 20.2 \\
\hline $34-2,63$ & 16.0 & 24.0 & 0.60 & 11.7 & 20.4 & 0.58 & 22.1 & 25.7 \\
\hline $34-2,134$ & 145.7 & 30.1 & 0.87 & 146.7 & 28.9 & 0.76 & 148.7 & 26.7 \\
\hline $34-3,77$ & 312.4 & 19.7 & 0.74 & 307.3 & 20.9 & 0.58 & 304.9 & 20.3 \\
\hline $34-3,140$ & 249.8 & 26.5 & 0.87 & 242.0 & 23.7 & 0.11 & 240.6 & 23.3 \\
\hline $34-4,48$ & 305.7 & 24.1 & 0.79 & 295.6 & 21.2 & 0.72 & 293.5 & 21.4 \\
\hline $34-4,116$ & 26.4 & 21.0 & 0.71 & 25.2 & 23.1 & 0.62 & 25.9 & 23.0 \\
\hline $53-1,78$ & 349.4 & 25.0 & 0.75 & 346.9 & 25.6 & 0.64 & 346.4 & 25.7 \\
\hline $35-2,21$ & 130.1 & 59.0 & 0.57 & 145.2 & 58.1 & 0.41 & 156.7 & 64.0 \\
\hline $35-2,103$ & 8.3 & 16.2 & 0.66 & 9.1 & 20.2 & 0.52 & 9.1 & 21.4 \\
\hline $35-3,17$ & 243.1 & 13.3 & 0.81 & 234.5 & 13.1 & 0.72 & 235.8 & 11.8 \\
\hline $35-3,94$ & 300.1 & 24.2 & 0.84 & 295.0 & 26.0 & 0.72 & 292.5 & 19.2 \\
\hline $35-4,32$ & 18.6 & 31.6 & 0.41 & 13.8 & 28.5 & 0.34 & 29.5 & 48.6 \\
\hline $35-4,110$ & 128.3 & 48.7 & 0.27 & 140.3 & 38.6 & 0.11 & 80.9 & -68.1 \\
\hline $35-5,53$ & 269.1 & 65.8 & 0.20 & 241.5 & 64.9 & - & - & - \\
\hline $35-5,126$ & 47.6 & 12.2 & 0.62 & 65.4 & 0.4 & 1.29 & 68.8 & -0.8 \\
\hline $36-1,97$ & 44.9 & 25.7 & 0.30 & 59.8 & 18.9 & 0.16 & 53.3 & 7.6 \\
\hline $36-2,35$ & 321.3 & 23.5 & 0.14 & 179.7 & 26.5 & 0.06 & 297.4 & 21.9 \\
\hline $36-2,106$ & 355.4 & 19.5 & 0.30 & 350.9 & 10.6 & 0.16 & 11.0 & 10.2 \\
\hline $36-3,39$ & 214.8 & 41.1 & 0.82 & 263.3 & 25.2 & 0.60 & 254.5 & 23.9 \\
\hline $36-3,119$ & 198.5 & 15.4 & 0.98 & 195.2 & 12.7 & 0.88 & 193.4 & 12.7 \\
\hline $37-1,55$ & 248.8 & 50.6 & 0.54 & 279.6 & 58.2 & 0.48 & 288.3 & 55.2 \\
\hline $37-1,102$ & 215.4 & 73.9 & 0.69 & 197.5 & 63.1 & 0.56 & 207.9 & 59.2 \\
\hline $38-1,126$ & 0.0 & 22.9 & 0.28 & 8.0 & 27.2 & 0.15 & 341.2 & 9.7 \\
\hline $38-2,33$ & 1.9 & 61.4 & 0.25 & 149.8 & 36.8 & 0.14 & 31.2 & 31.1 \\
\hline
\end{tabular}

Note: The declinations are measured from an arbitrary fiducial in each specimen.

For the most part, the NRM of the red limestone samples showed good stability to alternative field demagnetization, although unstable behavior seemed to characterize several samples from the lower sections of Core 35, the upper sections of Core 36, and Core 38. Red limestone samples which showed good directional stability typically had median demagnetizing fields greater than 100 oe (e.g., Samples 34-2, $134 \mathrm{~cm}$ and 35$2,21 \mathrm{~cm}$; Figure 3 ) whereas the more directionally unstable samples had lower values (e.g., Samples 36-2, $35 \mathrm{~cm}$ and 38-1, $126 \mathrm{~cm}$; Figure 3). One limestone sample (Sample 33-3, $88 \mathrm{~cm}$ ) had a stable reversed polarity (negative inclination); the magnetization intensity of this sample increased with progressive alternating field demagnetization to 100 oe (Figure 3 ), apparently in response to the removal of a softer component directed in opposition to the more stable reversed component of magnetization.

The magnetic inclinations of DSDP samples are meaningful because the vertical direction usually is known. It is therefore possible under favorable circumstances to determine from the inclinations the 
paleolatitude of the site at the time the remanent magnetization was acquired and to detect reversals of magnetization polarity in the cored sedimentary column provided the paleolatitude is sufficiently high. The NRM inclinations and the remanent inclinations after AF demagnetization in 100 oe and in 200 oe for the red limestone samples from Cores 33 to 38 are plotted with respect to stratigraphic position in Site 367 in Figure 4.

The most consistent inclinations occur in samples from Cores 33 and 34 . There are only relatively small changes in the remanent direction of each sample after AF demagnetization, characteristic of stable magnetizations. The mean inclination, irrespective of sign, for the 14 samples from the two cores is $27.7^{\circ}$ $\pm 9.7^{\circ}$ (SD) for NRM, $26.4^{\circ} \pm 8.1^{\circ}$ after 100 oe, and $25.0^{\circ} \pm 5.1^{\circ}$ after 200 oe; note the decrease in standard deviation with demagnetization.

The inclinations in samples from Cores 34 to 38 are less consistent overall, although in many of these samples, the magnetizations appear stable as there is little change in the inclination after AF demagnetization. The mean inclination for the 18 samples from these cores is near that for the samples from Cores 33 and 34 but there is greater scatter: $35.0^{\circ} \pm 20.0^{\circ}$ for $\mathrm{NRM}, 30.8^{\circ} \pm 19^{\circ}$ after 100 oe, and $28.9^{\circ} \pm 21.7^{\circ}$ after 200 oe.

The mean remanent inclination for the most reliable samples (Cores 33 and 34) is steeper than the inclination of the present magnetic field $\left(15^{\circ}\right)$ at the core site, but is near that of the geocentric axial dipole field $\left(24^{\circ}\right)$. The expected inclination at the site near the time of deposition of the limestones (late Jurassic) can be calculated from the mean paleomagnetic pole for Africa for the early Jurassic and early Cretaceous, the closest ages for which reliable data are available (Van der Voo and French, 1974): these give inclinations of $30^{\circ}$ and $21^{\circ}$, respectively. Therefore, on the basis of the average remanent inclination alone, it is not possible to determine whether the remanent magnetization is of recent origin or not. However, the occurrence of a reversed direction of magnetization within the predominantly normally magnetized section would suggest the remanence was acquired near the time of deposition of the limestone. If the basement at this site was formed during a period of the Jurassic with predominantly normal geomagnetic field polarity (Irving and Pullaiah, 1976), the reversed magnetization in the overlying limestone may represent the initial geomagnetic reversed interval in the late Jurassic-early Cretaceous magnetic reversal sequence (Larson and Pitman, 1972; Larson and Hilde, 1976).

\section{BASALTS}

Besides characterizing the remanent magnetic properties and magnetic mineralogy, this study was designed to measure the tendency of the basalts to acquire viscous remanent magnetization (VRM) and to evaluate its significance with respect to the remanent magnetic properties of the basalts from this site. Four stages of investigation were involved for this latter aspect: (1) measurement of natural remanent magnetic properties, (2) acquisition of VRM in the specimens

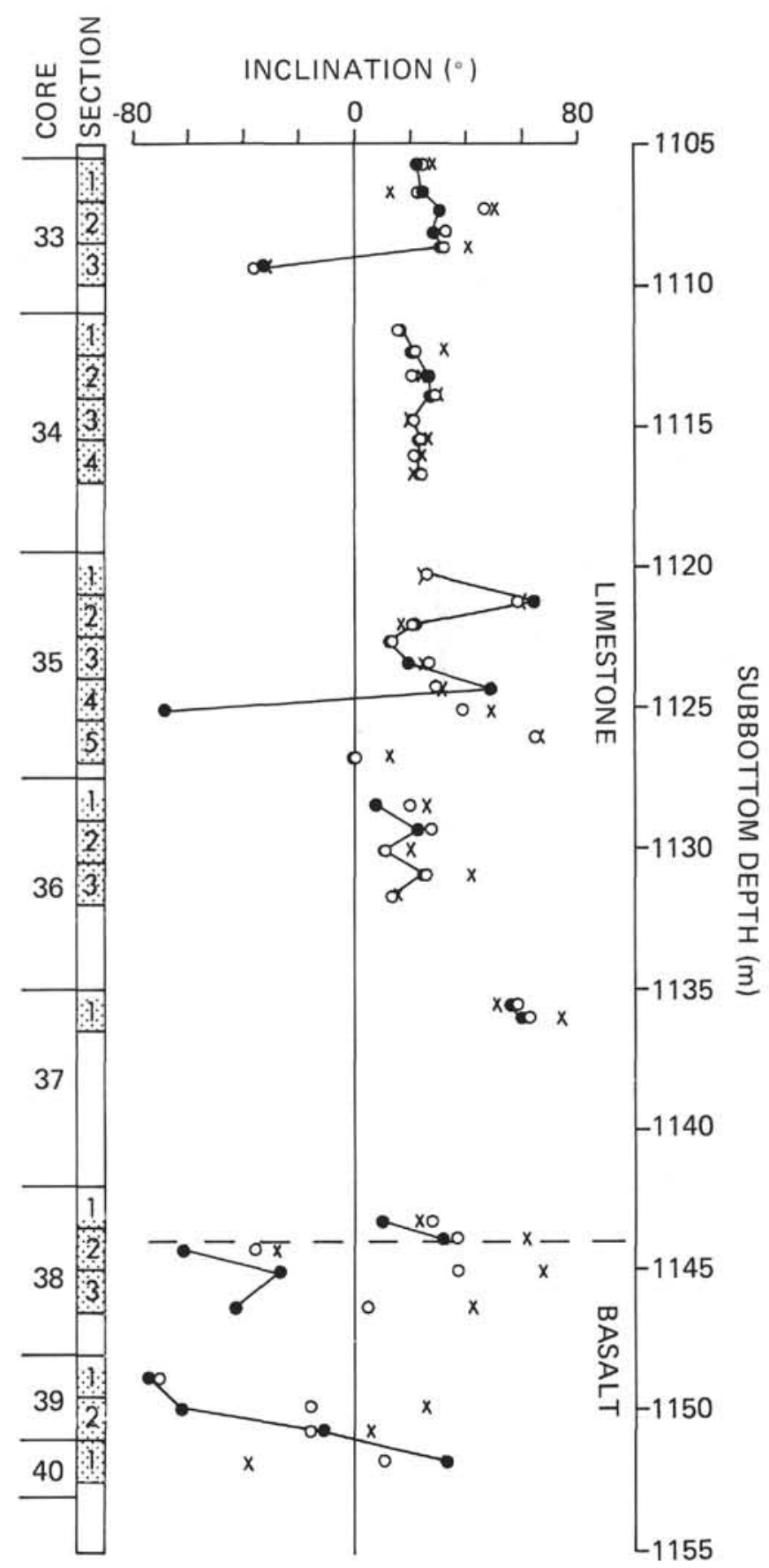

Figure 4. Inclination of natural remanent magnetization (NRM; X's) and after AF demagnetization in 100 oe (open circles) and 200 oe (filled circles) for red limestone and basalt samples plotted against subbottom depth in Site 367.

while they yet carried their original remanence, (3) alternating field (AF) demagnetization of the remanence after $500 \mathrm{hr}$ of VRM acquisition, and (4) acquisition of VRM in the same specimens under the same conditions and after AF demagnetization.

\section{NRM and $k$}

The remanent intensity and initial susceptibility of one specimen (Sample 39-1, $75 \mathrm{~cm}$ ) were very low (Table 
2); this specimen appeared intensively altered and brecciated. The NRM intensities of the remaining specimens gave a site mean value of $3.4 \times 10^{-3} \mathrm{G}$, and were well within the range of NRM intensities typically measured previously in other DSDP basalts (Lowrie, 1974). On the other hand, the initial susceptibilities of these specimens were generally toward the higher range of values previously measured in DSDP basalts (Lowrie, 1974) and gave a site mean (with the exception of Sample $39-1,75 \mathrm{~cm})$ of $5.8 \times 10^{-3} \mathrm{G} /$ oe.

Due to the high susceptibilities, the Königsberger ratios (NRM/Hk, H=0.35 oe) were generally low (Table 2), with a site mean of only 1.5. This value is considerably smaller than that typically found in most other DSDP basalts (Lowrie, 1974) and implies that although the remanence is the dominant magnetization component, induced magnetization effects cannot be neglected.

\section{Magnetic Mineralogy}

Curie point analysis was performed to determine the dominant magnetic mineralogy in these basalt specimens. Small chips of basalt were ground to a coarse powder and heated in air in a vertical motion type, automatically recording Curie balance. Temperature calibration was accurate to within $5^{\circ} \mathrm{C}$; magnetization measurements were uncalibrated. It was not possible to obtain a thermomagnetic curve for Sample 39-1, $75 \mathrm{~cm}$; the concentration of magnetic mineral in this specimen was evidently of insufficient concentration to produce a usable signal under the experimental conditions used.

The thermomagnetic curves of the remaining specimens were uniformly alike, very similar to the example shown in Figure 5. The thermomagnetic curves were irreversible, in some respects similar to those found in most rapidly quenched submarine basalts (Ozima and Ozima, 1971). Single Curie points were observed during heating and cooling, at about $390^{\circ} \mathrm{C}$ and $490^{\circ} \mathrm{C}$, respectively (Table 2 ). However, the room temperature magnetizations, before and after heating the samples to $600^{\circ} \mathrm{C}$, did not differ appreciably.

The Curie point observed during heating can be attributed to the presence of either titanomagnetite, or the cation-deficient form titanomaghemite as the dominant magnetic mineral. The irreversibility of the

TABLE 2

Natural Remanent Magnetism (NRM), Initial Susceptibility $(k)$, Konigsberger Ratio $\left(Q_{n}=\mathrm{NRM} / k H, H=0.35\right.$ oe $)$ and Curie Temperatures for Seven Basalt Samples from Site 367

\begin{tabular}{llcccc}
\hline $\begin{array}{c}\text { Sample } \\
\text { (Interval } \\
\text { in cm) }\end{array}$ & $\begin{array}{c}\mathrm{NRM} \\
\left(10^{-3} \mathrm{G}\right)\end{array}$ & $k\left(10^{-3} \mathrm{G} / \mathrm{oe}\right)$ & $Q_{n}$ & Heating & Cooling \\
\hline $38-2,76$ & 5.36 & 6.54 & 2.3 & 370 & 480 \\
$38-3,2$ & 3.84 & 6.80 & 1.6 & 380 & 485 \\
$38-3,129$ & 2.59 & 4.63 & 1.6 & 390 & 480 \\
$39-1,75$ & 0.077 & 0.22 & 1.0 & - & - \\
$39-2,35$ & 2.78 & 6.02 & 1.3 & 400 & 490 \\
$39-2,122$ & 1.39 & 5.40 & 0.7 & 390 & 500 \\
$40-1,87$ & 4.06 & 5.24 & 2.2 & 395 & 495 \\
\hline
\end{tabular}

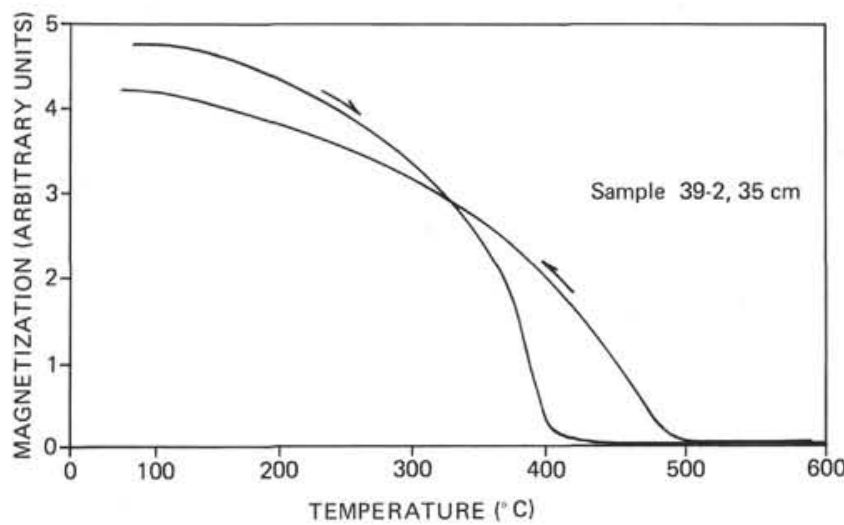

Figure 5. Thermomagnetic curve for a representative sample of basalt from Site 367. Analysis was performed in air in a field of 3000 oe.

curves is probably an effect of phase separation upon heating of the initially homogeneous titanomagnetite or titanomaghemite to form a titanium-rich phase such as hemo-ilmenite and a low-titanium titanomagnetite. However, the Curie point temperatures measured during heating of these samples are somewhat high, whereas the Curie point temperatures measured during cooling are rather low, compared to heating and cooling Curie point temperatures measured previously in other DSDP basalts. Lowrie (1974) observed initial Curie temperatures in the range $100^{\circ} \mathrm{C}$ to $400^{\circ} \mathrm{C}$ and a mean final Curie Temperature of $530^{\circ} \mathrm{C}$ in 123 thermomagnetic analyses of DSDP basalts. For titanomagnetites $\left[\mathrm{xFe}_{2} \mathrm{TiO}_{4} \cdot(1-\mathrm{x}) \mathrm{Fe}_{3} \mathrm{O}_{4}\right]$ the composition parameter, $x$, which defines the ulvospinel proportion in the titanomagnetite solid solution, determines the initial Curie temperature. After phase separation, the low-titanium magnetite product should have an $x$ value of about 0.05 (Nagata, 1962). Lowrie (1975) determined a mean $x$ value of 0.085 for the average final Curie temperature in 123 samples of DSDP basalt, in reasonable agreement with the expected $x$ value. The mean final Curie temperature for the six basalt samples studied here was $485^{\circ} \mathrm{C}$, corresponding to an $x$ value of 0.21 ; apparently phase separation was inhibited from closely approaching completion in these samples. The apparent incomplete phase separation can, in part, account for the lack of an appreciable increase in room temperature saturation magnetization after thermal cycling that is common to most submarine basalts previously studied (e.g., Ozima and Ozima, 1971; Lowrie, 1974).

\section{Viscous Remanent Magnetization Experiments}

The specimens were placed in a 1-oe field directed along the cylindrical axis ( $z$ axis) of each specimen. Large Helmholtz coils were used to provide a uniform field throughout the region used for this experiment and to cancel other field components. Each specimen was removed from the field-controlled region at periodic intervals for a few minutes, and its remanence was remeasured on the spinner magnetometer. The experiment was continued for $500 \mathrm{hr}$ ( $3 \mathrm{wk}$ ) during which the growth of VRM in each specimen was 
frequently monitored. The VRM was calculated by subtracting the original NRM measurements from the remanence at each successive stage of VRM acquisition. This first VRM, acquired in the presence of the NRM of the specimen, is referred to as VRM1.

\section{NRM Direction and Stability}

The AF-demagnetization characteristics of the specimens were uniformly alike. VRM1 was removed first, then the original NRM was demagnetized; at fields of 300 oe and higher indications of remagnetization by acquisition of anhysteretic remanence became apparent. The ratio of the remanent intensity after 100oe AF treatment to the original NRM intensity was low, ranging from $2 \%$ to $39 \%$ and averaging only $18 \%$, while after 200 -oe AF treatment, only from $1 \%$ to $10 \%$ (4\% of average) of the original NRM intensity remained (Table 3 ). Clearly the NRM contained a very large low coercivity component that could be influenced by relatively low magnetic fields.

The NRM inclination directions were very variable, both in absolute value and in sign (Table 3; Figure 4). Although the inclinations after 200 oe were more consistent the AF demagnetization characteristics of individual specimens did not indicate strongly that stable directions were isolated. The mean inclination (regardless of sign) after 200 oe for the seven specimens is $44.6^{\circ} \pm 22.5^{\circ}$ (SD). This mean inclination is much steeper than the inclination of the present field $\left(15^{\circ}\right)$ or the geocentric axial dipole field $\left(24^{\circ}\right)$ at the site. Moreover, it is substantially steeper than the expected inclination at the site, as calculated from the mean paleomagnetic pole for Africa (Van der Voo and French, 1974) for the early Jurassic (inclination $=30^{\circ}$ ) or the early Cretaceous (inclination $=21^{\circ}$ ); the age of basement at Site 367 , which is on the African plate, should lie within these age limits. Apparently, the basalts measured do not record well any known average geomagnetic dipole field since the early Jurassic at the site location. It is possible that an insufficient duration of time is represented by these basalts to average to zero the effects of secular variation. However, it is more likely a stable component of magnetization was simply not isolated.

\section{VRM Characteristics}

The VRM acquisition in all seven basalt specimens followed the same behavior as shown for a representative specimen in Figure 6 . The change in total

TABLE 3

Declination (D) and Inclination (I) of Natural Remanent Magnetization (NRM) and the Direction and Percentage of Initial NRM Intensity Remaining After Alternating Field Demagnetization in 100-oe and 200-oe for Site 367 Basalt Samples

\begin{tabular}{|c|c|c|c|c|c|c|c|c|}
\hline \multirow{2}{*}{$\begin{array}{c}\text { Sample } \\
\text { (Interval } \\
\text { in } \mathrm{cm} \text { ) }\end{array}$} & \multicolumn{2}{|c|}{ NRM } & \multicolumn{2}{|c|}{100 oe } & \multirow{2}{*}{$\begin{array}{c}\mathrm{J}_{100} / \mathrm{J}_{\mathrm{NRM}} \\
(\%)\end{array}$} & \multicolumn{2}{|c|}{$200 \mathrm{oe}$} & \multirow{2}{*}{$\begin{array}{c}\mathrm{J}_{200} / \mathrm{J} \\
\text { NRM } \\
(\%)\end{array}$} \\
\hline & D & 1 & D & I & & D & I & \\
\hline $38-2,76$ & 250 & -28 & 247 & -36 & 27 & 245 & -62 & 5 \\
\hline $38-3,2$ & 171 & 67 & 318 & 37 & 2 & 14 & -27 & 2 \\
\hline $38-3,129$ & 175 & 42 & 192 & 5 & 9 & 194 & -43 & 1 \\
\hline $39-1,75$ & 100 & -71 & 55 & -70 & 39 & 33 & -74 & 10 \\
\hline $39-2,35$ & 80 & 25 & 53 & -16 & 14 & 349 & -62 & 2 \\
\hline $39-2,122$ & 195 & 6 & 205 & -16 & 22 & 180 & -11 & 3 \\
\hline $40-1,87$ & 217 & -38 & 218 & 1 & 11 & 197 & 33 & 2 \\
\hline
\end{tabular}

Note: The delineations are measured from an arbitrary fiducial in each specimen. magnetization of the specimen with time is depicted as VRM1 in Figure 3. The acquisition of VRM1 in the 1.0-oe field over $500 \mathrm{hr}$ can be considered to have occurred in three stages: an initial stage of up to several hours during which little change in magnetization occurred, a second stage from several hours to about 100 hours where the acquisition of VRM was most rapid, and a final stage to the end of the experiment $(500 \mathrm{hr})$ where again little VRM acquisition occurred; similar three-stage VRM acquisition behavior has been noted in other DSDP basalts (Lowrie, 1974). In the same period there was also a change in the horizontal component of magnetization, that is, in the plane perpendicular to the applied field; this change is depicted as VRM1 (DH) in Figure 6. As no field component acted in this plane, the change in intensity reflects either relaxation of a magnetization in that plane, or reduction of that component of magnetization as very low coercivity components remagnetize in the direction of the applied field. The change in magnetization in the horizontal plane appears to be similar in form to the change in total magnetization of the specimen. However, the change in remanent magnetization in the horizontal plane represents on the average only about $25 \%$ (range $13 \%$ to $44 \%$ in the seven specimens) of the total VRM after $500 \mathrm{hr}$, the component parallel to the applied field constituting a major portion of the total change in magnetization.

After AF demagnetization of the combination of NRM and VRMI, the acquisition of a new VRM (VRM2) follows a strikingly different pattern (Figure 6). In this case, no systematic variation occurred in the horizontal plane so that VRM2 is essentially the change in magnetization parallel to the applied field of $1.0 \mathrm{oe}$. This change proceeded more slowly than for VRM1; after $500 \mathrm{hr}$, the intensity of VRM2 was typically less than $10 \%$ of VRM1 in each specimen (Table 4). Such a marked difference in VRM acquisition as an apparent function of the initial magnetic state of the sample was unexpected. The VRM2 experiment was repeated, but similar results to those after the initial AF demagnetization were obtained.

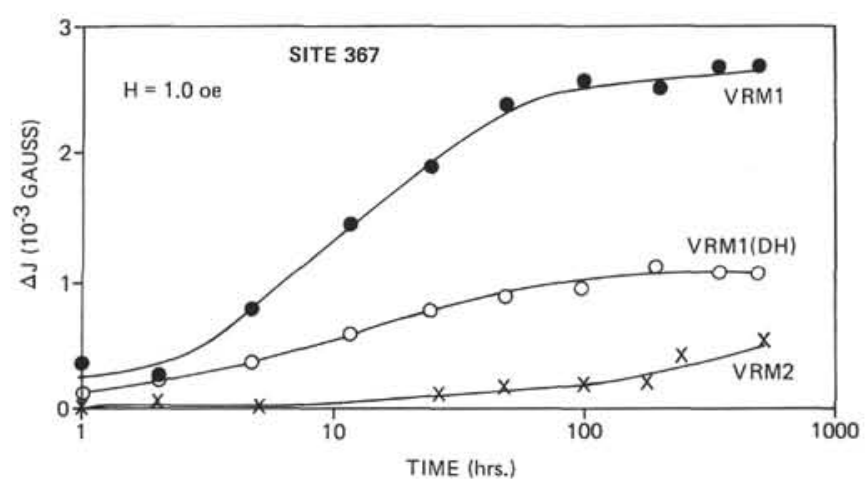

Figure 6. Change in remanent magnetization with time in an applied field of 1.0 oe in basalt sample $40-1,87 \mathrm{~cm}$. VRM1 is the change in total remanence and VRM1 (DH) is the change in the plane perpendicular to the applied field of the sample from the NRM state; VRM2 is the total change in remanences of the sample under similar conditions, but after AF demagnetization to $300 \mathrm{oe}$. 
TABLE 4

Magnetization Intensity of Natural Remanent Magnetization (NRM) Compared with the Intensity of Viscous Remanent Magnetization (VRM) Acquired over $500 \mathrm{hr}$ in a 1.0-oe Field Before (VRM1) and After (VRM2) Alternating Field Demagnetization

\begin{tabular}{llllcc}
\hline $\begin{array}{c}\text { Sample } \\
\text { (Interval } \\
\text { in cm) }\end{array}$ & NRM & VRM1 & VRM2 & VRM1/NRM & VRM2/NRM \\
\hline $38-2,76$ & 5.36 & 3.39 & 0.014 & 63 & $<1$ \\
$38-3,2$ & 3.84 & 3.65 & 0.25 & 95 & 7 \\
$38-3,129$ & 2.59 & 283 & 0.022 & 109 & 1 \\
$39-1,75$ & 0.077 & 0.047 & 0.0018 & 61 & 2 \\
$39-2,35$ & 2.78 & 1.47 & 0.26 & 53 & 9 \\
$39-2,122$ & 1.39 & 2.10 & 0.040 & 66 & 3 \\
$40-1,87$ & 4.06 & 2.71 & 0.20 & 67 & 5 \\
\hline
\end{tabular}

\section{Discussion}

The remanent magnetic properties of the basalts are very unstable. The NRM are dominated by very low coercivity components of magnetization which also characterize the remanence-carrying potential of these rocks. Laboratory-induced anhysteretic remanent magnetization (ARM) and isothermal remanent magnetization (IRM), which should receive contributions from the entire coercivity distribution in these basalts, had a similar low stability to alternating fields as the NRM (Figure 7), with median demagnetizing fields typically less than 100 oe (Table 5). However, the stability of ARM was marginally but consistently greater than that of IRM in each sample, implying the carriers of remanence are predominantly fine grained (Lowrie and Fuller, 1971; Johnson et al., 1974; Bailey et al., 1975). Since fine grained remanence carriers are usually considered to possess stable magnetic moments, it is difficult to reconcile the relative and absolute stabilities of ARM and IRM in these samples.

The intensity of VRM acquired in the specimens after AF demagnetization was only about one-tenth the VRM intensity acquired in the presence of the NRM (Figure 6; Table 4). Many previous reports of VRM in DSDP basalts (e.g., Lowrie, 1973, 1974; Pierce et al., 1974; Kent and Lowrie, in press) were based on VRM acquired from the demagnetized state. However, Lowrie and Kent (1976) also measured VRM acquisition before as well as after AF demagnetization in basalt samples from DSDP Leg 34; they found a $50 \%$ decrease in VRM intensity over $500 \mathrm{hr}$ when acquired from a demagnetized state. The present results and those of Lowrie and Kent (1976) suggest that an evaluation of the potential seriousness of VRM components in oceanic basalts be based on acquisition experiments performed in the presence of the NRM. Although it is not known how prevalent the apparent reduction is in VRM acquisition after AF demagnetization, it seems quite likely in light of these results that most previous reports of VRM in DSDP basalts may have underestimated viscous behavior of the rocks.

The 500-hr VRM amounted to a very large fraction (53\% to $109 \%$ ) of the NRM intensity when acquired from the NRM state. Since the laboratory VRM acquisition experiment performed in the presence of the behavior as it may occur in situ, we conclude that a significant portion of the NRM of these Site 367 basalts is due to VRM acquired very recently in the presence of the geomagnetic field.

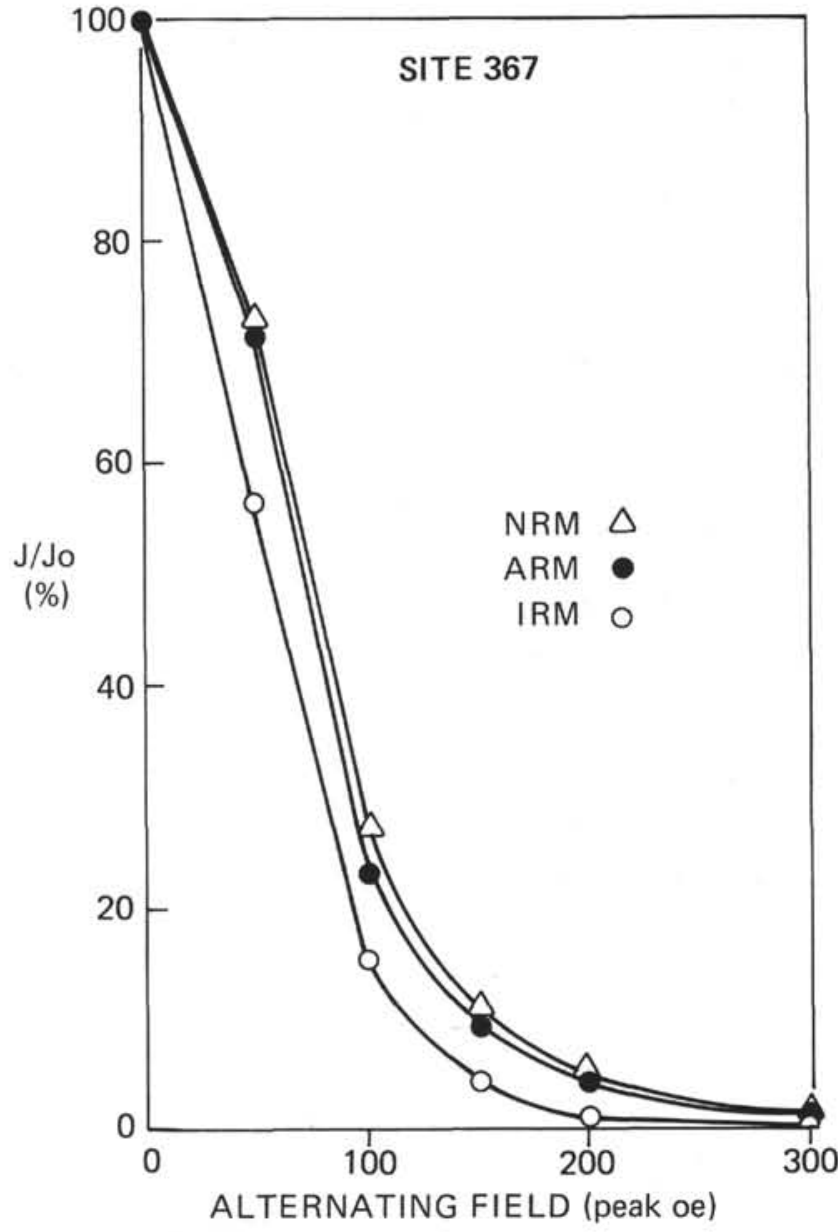

Figure 7: Normalized AF demagnetization curves of natural remanent magnetization (NRM), anhysteretic remanent magnetization (ARM), and isothermal remanent magnetization (IRM) for a basalt specimen (Sample 38-2, $76 \mathrm{~cm}$ ). ARM was produced in the sample in a $1.0 \mathrm{oe}$ direct field coaxial with a 2000-oe alternating field; IRM was produced in a 2000-oe direct field.

Lowrie (1973) has observed viscous behavior in basalts from several DSDP sites situated in regions of the World Ocean where lineated marine magnetic anomalies were poorly defined or absent. On the basis of this observation, he postulated that certain marine magnetic quiet zones may be due to viscous remag-

TABLE 5

Intensity and Stability Against Alternating Fields of Natural (NRM), Anhysteretic (ARM), and Isothermal (IRM) Remanent Magnetization for Seven Basalt Samples from Site 367

\begin{tabular}{llrrrrr}
\hline $\begin{array}{c}\text { Sample } \\
\text { (Interval } \\
\text { in cm) }\end{array}$ & \multicolumn{3}{c}{ Intensity $\left(10^{-3} \mathrm{G}\right)$} & \multicolumn{3}{c}{ MDF (oe) } \\
\hline $38-2,76$ & NRM & ARM $^{(a)}$ & IRM $^{(b)}$ & NRM & ARM & IRM \\
$38-3,2$ & 3.8 & 68.7 & 2582 & 75 & 72 & 58 \\
$38-3,129$ & 2.6 & 33.7 & 2153 & 36 & 40 & 33 \\
$39-1,75$ & 0.08 & 1.6 & 1546 & 32 & 70 & 48 \\
$39-2,35$ & 2.8 & 53.4 & 2018 & 87 & 131 & 74 \\
$39-2,122$ & 1.4 & 41.2 & 1809 & 39 & 41 & 32 \\
$40-1,87$ & 4.1 & 46.5 & 2058 & 36 & 69 & 46 \\
\hline
\end{tabular}

Note: Median demagnetizing field (MDF is the alternating field strength required to reduce the remanence to one-half its initial value. 
netization of the basalts underlying these regions. Site 367 is located near or within the magnetic quiet zone region identified by Hayes and Rabinowitz (1975) in the eastern North Atlantic. The basalts from this site were found to be magnetically unstable, dominated by low coercivity components of magnetization capable of carrying a large viscous magnetization. If these basalts are representative of the magnetized layer of the oceanic crust underlying the magnetic quiet zone in this area, the apparent lack of sea floor spreading-type anomalies may be due in part to reduction of magnetization contrast by viscous remagnetization rather than solely to the absence of geomagnetic reversals during the time interval this crust was believed to have formed.

\section{ACKNOWLEDGMENTS}

This work was supported by National Science Foundation Grant EAR 75-18955 and Office of Naval Research Contract N00014-75-C-0210.

\section{REFERENCES}

Bailey, M.E., Dunlop, D.J., and Buchan, K.L., 1975. Alternating-field demagnetization characteristics of pseudo-single-domain grains (abstract): E.O.S., v. 56, p. 353.

Hayes, D.E. and Rabinowitz, P.D., 1975. Mesozoic magnetic lineations and the magnetic quiet zone off northwest Africa: Earth Planet. Sci. Lett., v. 28, p. 105-115.

Irving, E. and Pullaiah, G., 1976. Reversals of the geomagnetic field, magnetostratigraphy, and relative magnitude of paleosecular variation in the Phanerozoic: Earth Sci. Rev., v. 12, p. $35-64$.

Johnson, H.P., Lowrie, W., and Kent, D.V., 1975. Stability of anhysteretic remanent magnetization in fine and coarse magnetite and maghemite particles: Geophys. J. Roy. Astron Soc., v. 41, p. 1-10.
Kent, D.V and Lowrie, W., in press. Magnetic properties of igneous rock samples from Leg 37. In Aumento, F., Melson, W.G., et al., Initial Reports of the Deep Sea Drilling Project, Volume 37: Washington (U.S. Government Printing Office).

Larson, R.L. and Hilde, T.W.C., 1976. A revised time scale of magnetic reversals for the Early Cretaceous and Late Jurassic: J. Geophys. Res., v. 80, p. 2586-2594.

Larson, R.L. and Pitman III, W.C., 1972. World-wide correlation of Mesozoic magnetic anomalies, and its implications: Geol. Soc. Am. Bull., v. 83 p. 3645-3662.

Lowrie, W., 1973. Viscous remanent magnetization in oceanic basalts: Nature, v. 243, p. 27-30.

1974. Oceanic basalt magnetic properties and the Vine and Matthews hypothesis: J. Geophys., v. 40, p. 513-536.

Lowrie, W. and Fuller, M., 1971. On the alternating field demagnetization characteristics of multidomain thermoremanent magnetization in magnetite: J. Geophys. Res., v. 76, p. $6339-6349$.

Lowrie, W. and Kent, D.V., 1976. Viscous remanent magnetization in basalt samples. In Hart, S.R., Yeats, R.S., et al., Initial Reports of the Deep Sea Drilling Project, Volume 34, Washington (U.S. Government Printing Office), p. 479-484.

Nagata, T., 1962, Magnetic properties of ferrimagnetic minerals of Fe-Ti-O system. In Benedum Earth Magnetism Symposium, Proc: Pittsburgh (University of Pittsburgh Press), p. 69-86.

Ozima, M. and Ozima, M., 1971. Characteristic thermomagnetic curve in submarine basalts: J. Geophys. Res., v. 76, p. 2051-2056.

Peirce, J.W., Denham, C.R., and Luyendyk, B.P., 1974. Paleomagnetic results of basalt samples from DSDP Leg 26, Southern Indian Ocean. In Davies, T.A., Luyendyk, B.P., et al., Initial Reports of the Deep Sea Drilling Project, Volume 26: Washington (U.S. Government Printing Office) p. 517-527.

Van der Voo, R. and French, R.B., 1974. Apparent polar wandering for the Atlantic-bordering continents: Late Carboniferous to Eocene: Earth Sci. Rev., v. 10, p. 99119. 